\title{
Application of Low-Cost Adsorbents for Pesticide Removal
}

\author{
Irina Gabriela CARA $^{1^{*}}$, Gerard JITĂREANU ${ }^{1}$ \\ ${ }^{1}$ Department of Pedotechnics, Faculty of Agriculture, "Ion Ionescu de la Brad"University of Agricultural \\ Sciences and Veterinary Medicine, 3, Mihail Sadoveanu Alley, Iasi 700490, Romania \\ * corresponding author: coroirina@yahoo.com
}

Bulletin USAMV series Agriculture 72(1)/2015

Print ISSN 1843-5246; Electronic ISSN 1843-5386

DOI 10.15835/buasvmcn-agr: 11182

\begin{abstract}
Pesticides released from agricultural practices are an important class of pollutants due to their reported toxicity even at trace levels. Therefore, pesticides removal is an increasing concern. Among various treatment methods, adsorption is supposed as the best one due to its inexpensiveness, universal nature and ease of operation. This review highlights and provides an overview of the use of cheap and non-pollutant materials as an viable alternative for pesticide and their metabolite adsorption process and removal technology. However, there is a lack of data on field scale application for testing of adsorption units using single biosorbents and their combinations to recover pesticides from soil-water system. This work describes a global assessment of the equilibrium modeling of biosorption processes as well as the structural, chemical and morphological modification and activation of biosorbents.
\end{abstract}

Keywords: adsorbent, pesticide, sorption.

\section{INTRODUCTION}

Pesticide contamination of water resources through agricultural activities is a worldwide environmental problem. At the same time and as a consequence of the huge population pressure, globalization and social civilization growth, pesticide are indispensable agents for the sustainable production of high-quantity agricultural food. Traces of these products are frequently detected in surface water and in some cases in groundwater, which is a major source of drinking water around the world. The frequent detection of many types of pesticide residues in natural waters is of great concern to the public, to authorities and to all those involved in potable water production (Plakas et al., 2012). In accordance with the European Community Drinking Water Directive pesticide level in drinking water should be less than $0.1 \mu \mathrm{L}^{-1}$. Apart from toxic effects, pesticide potential long-term health risks include different types of endocrine malfunction, interaction with estrogen and androgen receptors and thyroid function has been investigate to a limited extend while many long -term effects are still unidentified.

Therefore the prevention of water resources pollution is friendlier than fixing polluted aquifers. From this point of view is becoming an important concern to develop greener remediation technique that prevent leaching on land or avoid water contamination during filling and cleaning operations. It has been proven that the adsorption is considered an attractive method for the removal of different organic pollutants from environmental matrices due to its simplicity and ease of operation over other physical, biological and chemical technologies like precipitation followed by coagulation (Zolgharnein et al., 2011), membrane filtration (Farrukh et al., 2014, Qiu et al., 2013 and photochemical degradation (Sakkas et al., 2010). The use of biochar or activated carbon produced by carbonizing organic materials for 
removing pesticide is still very popular. Activated carbon and biochars have shown good pesticide molecules adsorption capacities. Over the last few years, a large number of investigations have been conducted to test the low cost adsorbents for the removal of pesticide molecules. Therefore, there is a growing demand to find relatively efficient, inexpensive and easily available adsorbents for the adsorption of pesticide (Rojas et al., 2014). Various types of biomass, such us agricultural crop straw, wood and animal manure have been introduced as promising agents to prevent and remove pesticide from water and soil in order to reduce the risk of these organic pollutants in groundwater contamination.

An overview of some agriculture low cost adsorbents is presented in this paper and their removal performance is assessed. From this goal, a fairly discussion of the current technologies available for pesticide removal without adverse impacts on the environment is provided, highlighting the main factors and the mechanism involved. This paper reviews (i) the recent progress in the application of various types of low cost adsorbents in the removal of toxic organic and inorganic pollutants from contaminated water; (ii) also describes their characteristics and (iii) several possible adsorption mechanisms and kinetics.

\section{Current technologies available for re- moval methods of pesticide:}

Pesticides are relatively stable and could produce severe toxicant impact to living beings, and tend to accumulate causing various diseases and disorders. There are different treatment systems available for the removal of hazardous agricultural chemicals that migrate to the environment, including, chemical coagulation, sedimentation, photochemical degradation, oxidation and adsorption. Because of the high cost, many of these conventional methods have not been widely applied at large scale.

Biological processes do not always provide satisfactory results and partial elimination of pesticides is achieved, since many of the organic substances produced by the chemical industry are toxic or resistant to biological treatment.

Chemical oxidation is generally expensive because the sludge formed during treatment tends to be more resistant to complete chemical degradation, and furthermore, they all consume energyand reagents.Advanced Oxidation Processes are among the most widely used technologies for industrial effluent treatment of water polluted by organic compounds characterized by their low biodegradability; complete mineralization of the organic contaminant can be achieved but their

Tab.1. Treatment technologies for the pesticide removal and associated advantages and drawbacks.

\begin{tabular}{|c|c|c|}
\hline Treatment & Advantages & Drawbacks \\
\hline Biological process & $\begin{array}{l}\text { Feasible in removing wide range } \\
\text { of pesticide which cannot be } \\
\text { treated by chemical or membrane } \\
\text { technologies. }\end{array}$ & $\begin{array}{l}\text { Large surface areas for } \\
\text { implantation and biomass } \\
\text { separation units. } \\
\text { Low digestion rates (days or } \\
\text { weeks). }\end{array}$ \\
\hline Advanced oxidation treatment & $\begin{array}{c}\text { Capable of treating multiple } \\
\text { pesticides in a single step. } \\
\text { Accelerating pesticide removal } \\
\text { via solar, UV-vis-rays or ultrasonic } \\
\text { radiation. }\end{array}$ & $\begin{array}{l}\text { Formation of by products (chlorine } \\
\text { or hypochlorite). } \\
\text { High energy costs for large-scaling } \\
\text { processes. } \\
\text { Extra energy sources (solar, Uv-vis- } \\
\text { rays or ultrasonic). }\end{array}$ \\
\hline Membrane technologies & $\begin{array}{l}\text { Operated without phase changes or } \\
\text { chemical conditioning. } \\
\text { Low energy consumption. }\end{array}$ & $\begin{array}{l}\text { Short lifetime of membranes and } \\
\text { process productivity. } \\
\text { Huge volume of concentrate (which } \\
\text { require further treatments). }\end{array}$ \\
\hline Fenton process & $\begin{array}{l}\text { High removal rates of organic and } \\
\text { inorganic, biodegradable and non- } \\
\text { biodegradable pesticides. } \\
\text { Ease of handling. } \\
\text { Low operational cost. }\end{array}$ & $\begin{array}{l}\text { Production of residual sludge. } \\
\text { Require large usage of chemical } \\
\text { reagents. }\end{array}$ \\
\hline
\end{tabular}


operational cost is relatively high (Catalkaya et al., 2009).

The advantages of fenton process is that it easy in handling, has a low operational cost and a rapid decomposition of organic and inorganic pesticide, but the residual sludge produced requires large usage of chemical reagents (Farre et al., 2007).

Recently, nanomaterials have been investigated for their potential to remove pesticide molecules from aqueous solutions. Impregnation, coprecipitation and ion exchange are the earliest methods for particle immobilization on supports (Pradeep et al., 2014). These methods are industrially feasible but have the drawbacks in the formation of large and inactive particle or low exchange efficiency leading to a limited number of cationic sites for nanoparticle formation.

In this moment, there is no single successfully process in controlling and removing pesticide because of the complex nature of the molecules. At large scale a mixture of different eco-friendly techniques are implemented only to obtain the desired quality in a competitive way.

The most commercially utilized method for the removal of toxic pollutants from water is adsorption, a surface phenomenon by which a fluid mixture is attracted to the surface of a solid adsorbent and forms attachments via physical and chemical bonds. This process is considered to be superior to other technique in terms of costs, simplicity of design, flexibility, ease of operation and insensitivity to toxic pollutants. Adsorption also does not result in the formation of harmful substances. Table 1 show the advantages and drawbacks of various techniques used for the removal of pesticide from wastewaters (Foo et al., 2010).

Activated carbon filtration is an adsorptive process in which the pollutant is adsorbed onto the surface of the carbon particles. The efficiency of the adsorption process is influenced by carbon characteristics, particle and pore size, surface area, solubility of the contaminant and contaminant attraction to the carbon surface. A variety of activated carbon materials have been used, such as granular activated carbon (GAC), powdered activated carbon (PAC), black carbon from wheat residues, carbon black and commercial activated carbon. The form GAC and PAC are the most used since are highly effective materials for removal of a variety of pesticides (De Wilde et al., 2009).

\section{Applications of low cost adsorbents:}

Of the many kinds of adsorbents (bacteria, filamentous fungi, sea materials, industrial waste, agricultural products, natural residues, sawdust, weeds, soil and ore materials) investigated for their potential to retain pesticide molecules, low cost adsorbents have proven to be efficient and economic in the removal of inorganic and organic pollutants from aqueous solution.

Throughout recent decades, a notable trend is the development of activated carbon or biochar from low cost adsorbents for its superior ability to remove a broad type of agrochemical pollutants dissolved in aqueous media. Biochar has structure and properties similar to activated carbon (AC), but the surface area of activated carbon is much larger and varies from a few hundred to thousands of $\mathrm{m}^{2} / \mathrm{g}$. Although the production of biochar is economical compared to AC because of the low energy operation of a simple process without activation.

Recently, Njoku et al. (2014) investigated sky fruit husk activated carbon (SFHAC) as adsorbent for the removal of herbicide bentazone. According to their studies SFHAC is a very promising adsorbent with large active surface area. Isotherm studies showed as the data were well fitted to Freundlich model, indicating a heterogeneous surface structure. It was also observed that the bentazone adsorbed by SFHAC decrease with increasing solution $\mathrm{pH}$.

Batchadsorption experiments wereperformed by De Wilde et al. (2009) to study adsorption potential of substrates used in biopurification system i.e. cow manure, straw, willow chopping, soil, coconut chips, garden waste compost, and peat mix for retention and leaching of metalaxyl, isoproturon, linuron, lenacil, bentazone and isoxaben. It can be concluded that the sorption capacity of the substrates was positively correlated with the organic carbon content, $\mathrm{CaO}$ content and the cation exchange capacity of the substrate material.

Rojas et al. (2014) used sunflower seed shells, rice husk, composted sewage sludge and soil for their potential as adsorbent for remove atrazine, alachlor, endosulfan sulfate and trifluralin molecules from aqueous solution. The study revealed that the maximum removal efficiency (73.9\%) was reached using $1 \mathrm{~g}$ of rice husk and $50 \mathrm{~mL}$ of pesticide solution $\left(200 \mu \mathrm{g} \mathrm{L}^{-1}\right)$. A pseudo 
first order model was found to be more suitable for the sorption of atrazine and alachlor while the pseudo second order best described endosulfan sulfate and trifluralin adsorption.

Somaia G Mohammad (2013) investigated the role of apricot stone activated carbon as an adsorbent of pesticide ethoprophos as a function of adsorbent dose, pesticide concentration, contact time and temperature. The monolayer sorption capacity of the adsorbent was found as $20.04 \mathrm{mg}$ $\mathrm{g}^{-1}$ by using Langmuir equation. The kinetic data were best described by the pseudo-second order model. The adsorption process was spontaneous and endothermic in nature.

Ken-Lin Chang et al. (2011) reported the effectiveness and feasibility of rice straw activated carbon as a low cost adsorbent for removing carbofuran from aqueous solution. The effects of several parameters such us contact time, $\mathrm{pH}$, temperature and the biosorbent dosage were studied. Adsorption capacity of carbofuran increased with increase in carbofuran concentration but decreased with increase in $\mathrm{pH}$ and temperature.

Huguenot et al. (2010) have tested the biosorption potential of sugar beet pulp, corncob, corncob char, perlite, vermiculite, sand and sediment for effective removal of glyphosate, diuron and 3,4-dichloroaniline (3,4-DCA) as single or mixed compounds. The major result is that sugar beet pulp and sand requires no preliminary treatment for diuron and 3,4-DCA, and were able to retain more than $50 \%$ of the corresponding pollutant at the studied concentration. Another finding is that the interactions between herbicides led to significant differences in their sorption when tested in mixtures. Further investigations are required on a larger scale to test the accuracy of these low cost sorbents in field conditions.

The efficiency of corn cob, olive kernels, soya stalks and rape seed stalks- activated carbon (AC) for the recovery of acaricide bromopropylat have been studied by Ioannidou et al. (2010). The kinetic analysis showed that pseudo secondorder model is applicable to all samples, while the equilibrium study showed that the Langmuir model is best fitted the isotherms. The AC with the higher adsorption capacity for bromopropylate was proved to be corn cob, then olive kernel and soya stalk, while rapeseed stalks gave the lower results for the specific application.
Tartakova et al. (2013) have applied biochar prepared from wheat straw (Triticum aestivum $L$.) and used in addition to agricultural soils to increase sorption of (4-chloro-2-methylphenoxy)acetic acid (MCPA) and other related processes such as leaching, dissipation and toxicity for sunflowers. Enhanced sorption of MCPA in the biocharamended soil resulted in a significant decrease of its leachability in soil columns as well as its dissipation in soil. Moreover, the phytotoxic effects of MCPA on sunflowers remained unchanged when soil was amended by wheat straw biochar.

Amberlyst - 15 a strongly acid cation exchange resin was used as an efficient adsorbent for the removal of malathion, a widely used organophosphorous pesticide. The removal rate of malathion was rapid and equilibrium was established within $30 \mathrm{~min}$, where $96 \%$ malathion was absorbed by this resin. The equilibrium data was fitted to the Freundlich isotherm model as evident from the values of correlation coefficient $>0.999$. Amberlyst -15 resins could be a potential candidate for the removal and recovery of highly toxic malathion from aqueous solution and can be used in environmental pollution control (Naushad et al., 2014).

\section{Factors affecting adsorption:}

1. Beside the type and chemical structure of the substrate, a number of physico-chemical factors affect adsorption efficiency at various extents. Important factors include:

2. Solution $\mathrm{pH}$ has a pronounced effect on the adsorption capacity because is changing the pesticide solubility and uptake capacity over the adsorbent surface. Gupta et al., (2001) studied the behaviour of DDD and DDE onto bagasse fly ash in $\mathrm{pH}$ conditions range from 2 to 9 . Increasing $\mathrm{pH}$ had positive effect, after which in basic solutions removal efficiency decreased. El Bakouri et al., (2009) observed that raising $\mathrm{pH}$ from 2 to 10 decreased biosorption efficiency of endosulfan sulphate using bamboo canes, date stones, peanut shells, and avocado stones. In acidic solutions, the surface of the sorbents becomes more positive and thereby the interaction between sorbents and polar pesticide increases.

3. Temperature of the solution which when increased, removal efficiency decreases by the greater solubility of the pesticide. Gupta et al., 
(2001) explored temperature dependence of DDD and DDE by bagasse fly ash in the range from $30-50^{\circ} \mathrm{C}$. It was found as long as the initial sorbate concentration is low changing the temperature had no effect on removal capacities. At higher initial concentration increasing temperature decreased removal efficiencies.

4. Initial pollutant concentration, generally increases the adsorption capacity with the increase of adsorbent quantity, however the removal percentage decreases.

5. Adsorbent nature, specific surface area, pore size distribution and presence of surface functional groups are of major importance towards pesticide molecules uptake from aqueous solutions.

6. Adsorbent dosage is also an important parameter as it determines the adsorption capacity of an adsorbent for a given initial concentration. Memon et al., (2007) reported a rapid increase of sorption percent by increasing the amount of sorbent dosage.

7. The initial contact time provides a rapid adsorption rate due to the abundant availability of active site and then gradually become slow till the equilibrium is attained. Naushad et al., (2014) observed that the sorption of malathion on Amberlyst - 15 cation exchange resin was very fast within 5 min and become slow after $30 \mathrm{~min}$, untill the equilibrium was established.

8. Modification and activation of adsorbents: specific surface area, pore size distribution, pore volume and presence of surface functional groups are factors which influence the adsorption capacity of adsorbents; to obtain the desired physical and chemical properties to enhance their efficiency towards pesticide molecule uptake from aqueous solution, adsorbent may be modified and adapted. Adsorption capacity increases with increase in specific surface area due to the availability of a number of adsorption sites, while pore size and micropore distribution are closely related to the composition of the adsorbents and the type of biomass raw material supplied for their synthesis (Ruthven D., 1984). The techniques of modification of biochar/activated carbon can be classified in two groups: carbonization and activation. The production of biochar includes one step, by pyrolysis - a carbonization process in which the content of carbon increases with temperature together with the elimination of oxygen and hydrogen contents. Generally biochar is a not complete carbonized product because its production is operated under low temperatures $\left(<500^{\circ} \mathrm{C}\right)$ or limited oxygen conditions (Zheng et al., 2010). In contrast, the production of activated carbon includes two stage processes: carbonization and activation. After physical and chemical activation, the surface areas and internal pore structures of activated carbon are greatly enhanced and improved compared to biochar that only experiences the carbonization treatment. However, biochar may act as a prematerial to obtaine activated carbon.

\section{Equilibrium adsorption isotherms:}

Equilibrium isotherm models are usually classified into empirical equations and the mechanistic models (Gautam et al., 2014). The mechanistic equation is able to represent and also to explain and predict the experimental curve but do not reflect the mechanism. Some empirical models for single solute systems are listed in Table 2. The Langmuir model and Freundlich model are the most common used in literature. As described by Rojas el al (2013) the Langmuir model involves monolayer sorption on a set of different localized sorption sites with uniform energies while the Freundlich approach is characteristic for heterogeneous surface and infinite surface coverage resulting from extremely strong solutesolute interaction. The models were initially developed for gas phase adsorption in monolayer and can be implemented to correlate pesticide adsorption processes.

The Langmuir isotherm assumes that adsorption takes place at a specific number of sites where the pesticide molecules can be adsorbed without any interactions between adsorbed species (Fomina et al., 2014).

At lower concentrations, an alternate isotherm developed by Herbert F. Freundlich frequently describes the data better. Freundlich isotherm relates the adsorption of pesticide molecules on a wide variety of adsorbents. On average, a favorable adsorption tends to have Freundlich constant $n$ between 1 and 10. Larger values of $n(>1 / n)$ imply stronger interaction between adsorbent 
Tab. 2. Adsorption models reported in the literature.

\begin{tabular}{ccc}
\hline Isotherm & Equation & Linear form \\
\hline Freundlich & $\mathrm{q}_{\mathrm{e}}=\mathrm{K}_{\mathrm{f}} \mathrm{C}_{\mathrm{e}}^{1 / \mathrm{n}}$ & $\log \mathrm{q}_{\mathrm{e}}=\log \left(\mathrm{K}_{\mathrm{f}}\right)+\log \left(\mathrm{C}_{\mathrm{e}}\right)$ \\
\hline Langmuir & $\mathrm{q}_{\mathrm{e}}=\frac{q_{m} K_{L} C_{e]}}{1+K_{L} C_{e}}$ & $\frac{C_{e}}{q_{e}}=+\frac{C_{e}}{Q_{m}}$ \\
\hline Redlich-Peterson (R-P) & $\mathrm{q}_{\mathrm{e}}=\frac{K_{R P} C_{e}}{1+\alpha_{R P} C_{e}^{\beta}}$ & $\ln \left[\left(\frac{K_{R P} C_{e}}{q_{e}}\right)-1\right]=\ln \alpha_{R P}+\beta \ln \mathrm{C}_{\mathrm{e}}$ \\
\hline Temkin & $\mathrm{q}_{\mathrm{e}}=\frac{R T}{b} \ln \left(\mathrm{K}_{\mathrm{t}} \mathrm{C}_{\mathrm{e}}\right)$ & $\mathrm{Q}_{\mathrm{e}}=\frac{R T}{b} \ln \mathrm{K}_{\mathrm{T}}+\frac{R T}{b} \ln \mathrm{C}_{\mathrm{e}}$ \\
\hline
\end{tabular}

and pesticide while $1 / \mathrm{n}$ equal to 1 indicates linear adsorption leading to identical adsorption energies for all sites.

\section{Kinetic studies:}

The kinetics of adsorption process is important in order to conclude the efficacy and also to identify the adsorption mechanism type based on physical and chemical properties of adsorbent and pesticide.

\section{Pseudo-first-order kinetic model}

The pseudo-first-order kinetic model was proposed by Largergren that can be represented by the following equation:

$\mathrm{q}_{\mathrm{t}}=\mathrm{q}_{\mathrm{e}}\left(1-\exp ^{-\mathrm{k}}{ }_{1} \mathrm{t}\right)$

where $\mathrm{k}_{1}(1 / \mathrm{h})$ is the pseudo-first-order rate constant and $t(h)$ is the contact time.

The linearized form of this model can be written as follows:

$\log \left(\mathrm{q}_{\mathrm{e}}-\mathrm{q}_{\mathrm{t}}\right)=\log \left(\mathrm{q}_{\mathrm{e}}\right)-\frac{k t}{2303}$

where $\mathrm{q}_{e}$ the amount of pesticide adsorbed onto substrates at equilibrium $(\mathrm{mg} / \mathrm{g})$ and $\mathrm{q}_{\mathrm{t}}$ is the amount $(\mathrm{mg} / \mathrm{g})$ of pesticide adsorbed at any time ( $\mathrm{min}$ ) and $\mathrm{k}_{1}$ is the rate constants of pseudo-first-order model.

Pseudo-second-order kinetic model

The pseudo-second-order kinetic model can be expressed as:

$$
\mathrm{q}_{\mathrm{t}}=\frac{q_{\theta}^{2} t k_{2}}{1+q_{\theta} k_{2} t}
$$

The linearized form of the above pseudosecond order kinetic model can be written as:

$$
\left.\frac{t}{q_{t}}=(\quad)+\right) \mathrm{t}
$$

where $\mathrm{k}_{2}$ is the rate constant of second-order model kinetic.

The initial sorption rate, $\mathrm{h}$ (mg/g min), when $\underline{t} \mapsto 0$ can be defined as:

$$
\mathrm{h}=\mathrm{k}_{2} \mathrm{q}_{\mathrm{e}}^{2}
$$

The pseudo-second-order expression was used to describe chemisorption involving valency forces through the exchange of electrons between the adsorbent and adsorbate as covalent forces and ion exchange. The advantage of using this model is that there is no need to know the equilibrium capacity from the experiments, as it can be calculated from the model. In addition the initial adsorption rate can also be obtained from the model. The rate of the adsorption uptake of pesticide molecules and hydrodynamic parameters are information offered by kinetic model which are important for the design of adsorption process.

\section{CONCLUSION}

The role of non-conventional low cost adsorbents in water treatment and waste management has been presented. Various agriculture products have been converted into low cost adsorbents and used as a promising material for the removal of pesticide molecules from water. The adsorption process could be generally modelled by Freundlich and Langmuir isotherms. However, other models 
such as Redlich-Peterson, Dubinin KR, Tempkin, BET are also used. The various parameters such as adsorption capacity, adsorption intensity, and energy of adsorption can be determined by linear regression.

The adsorption could be influenced by a number of factors, such as, adsorbent dose and size, contact time, agitation speed, temperature, $\mathrm{pH}$. Generally percent adsorption increased with increased adsorbent dose, contact time, and agitation speed. However, adsorption capacity varies depending on the characteristics of the adsorbents. For each type of material, there is an optimum $\mathrm{pH}$ range in which maximum adsorption is attained.

Beside, a number of papers published on adsorption there is little information on comparison between sorbents, a big gap in study of multipesticide-system and also in removing pesticide at $\mu \mathrm{g} \mathrm{mL} \mathrm{m}^{-1}$ concentration. Therefore, there is a great need to find out the practical utilization of agriculture waste as low cost adsorbents at commercial scale.

Acknowledgments: This paper was published under the frame of European Social Fund, Human Resources Development Operational Programme 2007-2013, project no. POSDRU/159/1.5/S/ 132765.

\section{REFERENCES}

9. Bakouri HE, Marillo J, Usero J, Ouassini A (2009). Natural Attenuation of Pesticide Water Contamination by using Ecological Adsorbents: Application for Chlorinated Pesticides included in European Water Framework Directive. J. Hydrol 364:175-181.

10. Bumpus JA, Tien M, Wright D, Aust SD (1985). Oxidation of persistent environmental pollutants by a white rot fungus. Science:1434-1436.

11. Catalkaya EC, Kargi F (2009). Advanced Oxidation and Mineralization of Simazine using Fenton Reagent. J. Hazard. Mater 168:688-694.

12. Farre MJ, Domenech X, Peral J (2007). Combined PhotoFenton and Biological Treatment for Diuron and Linuron Removal from Water Containing Humic Acid. J. Hazard. Mater 147:167-174.

13. Farrukh S, Hussain A, Iqbal N (2014). Fabrication and characterization of microfiltration blended membranes. Desalin Water Treat 52:1833-1840.

14. Fomina M, Gadd GM (2014). Biosorption: current perspectives on concept, definition and application. Bioresource Technology 160: 3-14.
15. Foo KY, Hameed BH (2010). Detoxification of pesticide waste via activated carbon adsorption process. J. Hazard. Mater 175:1-11.

16. Gautam RK, Mudhoo A, Lofrano G, Chattopadhyaya MC (2014). Biomass-derived biosorbents for metal ion sequestration: Adsorbent modification and activation methods and adsorbent regeneration. Journal of Environmenatl Chemical Engineering 2:239-259.

17. Gupta VK, Ali I (2001). Removal of DDD and DDE from wastewater using bagasse fly ash a sugar industry waste. Water Res 35:33-40.

18. Huguenot D, Bois P, Jézéquel K, Cornu JY, Lebeau T (2010). Selection of low cost materials for the sorption of copper and herbicides as single or mixed compounds in increasing complexity matrices. Journal of Hazardous Materials 182:18-26.

19. Ioannidou OA, Zabaniotou AA, Stavropoulos GG,. Islam MdA, Albanis TA (2010). Preparation of activated carbons from agricultural residues for pesticide adsorption. Chemosphere 80:1328-1336.

20. Memon GZ, Bhanger MI, Akhtar M (2007). The removal Efficiency of Chestnut shell for selected Pesticides from Aqueous Solutions. J. Colloid Interface Sci. 315:33-40.

21. Naushad M, ALOthman ZA, Khan MR, AlQahtani NJ, ALSohaimi IH (2014). Equilibrium, kinetics and thermodynamic studies for the removal of organophosphorus pesticide using Amberlyst - 15 resin: Quantitative analysis by liquid chromatography - mass spectrometry. Journal of Industrial and Engineering Chemistry.

22. Njoku VO, Azharul Islam MD, Asif M, Hameed BH (2014). Utilization of sky fruit husk agricultural waste to produce high quality activated carbon for the herbicide betazon adsorption. Chemical Engineering Journal 251:183-191.

23. Plakas VK, Anastasios JK (2012). Removal of pesticide from water by NF and RO membranes - A review. Desalination 287: 255-265.

24. Pradeep TA, Bootharaju MS (2014). Detection and Extraction of Pesticides. Chapter 16:241-270.

25. Qiu YR, Mao LJ (2013). Removal of heavy metal ions from aqueous solutions by ultrafiltration assisted with copolymer of maleic acid and acrylic acid. Desalination 329:78 -85

26. Rojas R, Vanderlinden E, Morillo J, Usero J, El Bakouri H (2014). Characterization of sorption processes for the development of low-cost pesticide decontamination techniques. Science of the Total Environment 488-489: 124-135.

27. Ruthven DM (1984) . Principles of Adsorption and Adsorption process. $1^{\text {st }}$ ed., John Wiley \& Sons, New York.

28. Sakkas VA, Islam MA, Stalikas C, Albanis T (2010). Photocatalytic degradation using design of experiments: a review and example of the Congo red degradation. J. Hazard. Mater 175: 33-44.

29. Tatarkova V, Hiller E, Vaculı'k M (2013). Impact of wheat straw biochar addition to soil on the sorption, leaching, dissipation of the herbicide (4-chloro-2-methylphenoxy) acetic acid and the growth of sunflower (Helianthus 
annuus L.). Ecotoxicology and Environmental Safety 92:215-221

30. Zheng W, Guo M, Chow T, Bennett DN, Rajagopalan N (2010). Sorption properties of greenwaste biochar for two triazine pesticide. Journal of Hazardous Materials 181: 121-126.
31. Zolgharnein J, Ali S, Jahanbakhsh G (2011). Pesticide removal using conventional and low cost adsorbents: A review. Clean - Soil, Water 39 (12):1105-1119. 